\title{
Mosquito repellent finishes on textile fabrics (woven \& knit) by using different medicinal natural plants
}

\begin{abstract}
In textile, Finishing is one of the significant processes which augment the performance of the fabric and functional properties as well. Health is always thought to be an indispensable requirement for human beings to live without any stress and it aids to give the best output of any work. Hygiene is also one of the important elements to live comfortably. A mosquito repellent textile protects the human beings from the bite of mosquitoes and ensures safety from the diseases like malaria and dengue fever. Medicinal plants like neem (Azadirachta indica), tulashi (Ocimum tenuiflorum) \& mint-leaf (Mentha) etc. are used for induction of organic mosquito repellent activity and all of them are ecofriendly. This project is an exiguous endeavor in developing an eco-friendly mosquito repellent finished fabric using the herbal extract from neem, tulshi and mint-leaf. The extracted chemicals are finished on to the fabric by pad-dry-cure process \& exhaust process and are evaluated using a mosquito repellency activity test .Then the repellency behavior of fabrics were checked after washing at three intervals $-5^{\text {th }}, 7^{\text {th }} \& 9^{\text {th }}$ washes . Finally, the finished fabrics showed a great amount of mosquito repellent activity for both knit and woven fabric which was calculated in percentage.
\end{abstract}

Keywords: mosquito-repellency, neem, tulshi, mint, excito chamber
Volume 6 Issue 4 - 2020

\author{
Mynul Islam Sajib,' Burhan Uddin Banna,' \\ Rony Mia, ${ }^{1,2}$ Bulbul Ahmed, ${ }^{3}$ Rittick Chaki,' \\ Syed Samiul Alam,' 'Md Abu Rasel,' Md \\ Tanjirul Islam' \\ 'Department of Textile Engineering, National Institute of Textile \\ Engineering \& Research (NITER), Bangladesh \\ ${ }^{2}$ College of Chemistry \& Chemical Engineering, Wuhan Textile \\ University, China \\ ${ }^{3}$ Department of Textile, Apparel \& Merchandising, Louisiana \\ State University, USA
}

\begin{abstract}
Correspondence: Rony Mia, Lecturer, Department of Textile Engineering (Wet Processing), National Institute of Textile Engineering \& Research (NITER), Savar, Dhaka- I350, Bangladesh, Tel+880-19275 I5370,Emailmroni_mia@niter.edu.bd
\end{abstract}

Received: July 22, 2020 | Published: August 21, 2020

\section{Introduction}

Mosquito repellent is a substance or finishing process applied to skin, cloths, other surface which repels away mosquitos. ${ }^{1}$ There are 3000 species of mosquitos, but only three members are responsible for the fatal diseases. Only female mosquitos have the mouth parts necessary for sucking blood. So they are responsible for the diseases like malaria, Dengue, Yellow fever, Chikungunia etc. ${ }^{2,3}$ Some mosquitoes can be found 200 miles from their birthplace. One species of Anopheles frequently becomes frozen but after gradual thawing revives and is capable of laying eggs. Of all the harmful creatures on earth, this little "vampire" probably poses the greatest threat to mankind. Mosquitoes transmit diseases to more than $700,000,000$ people annually and will be responsible for the deaths of 1 out of every 17 people currently alive. Malaria results from infection with a protozoan carried by Mosquitoes and, according to reports from the World Health Organization, cause as many as 3,000,000 deaths annually. It is responsible for yellow fever, dengue, hemorrhagic fever, epidemic polyarthritis, and several forms of encephalitis. ${ }^{4}$ Because of global warming the distribution of mosquitoes has expanded from topical region to northern latitudes, and that leads to a spread in sources of viral infection from mosquitoes. The use of effective insect repellents provides certain public health benefits. During the $3^{\text {rd }}$ World War many people have died because of the disease caused by mosquito. There is no effective vaccine for malaria. In the modern era "Smart Textile" is became a buzzword. Protective Textile is also a part of smart technology of textile. By using this part human beings solves many problems and mosquito repellent textile is one of them. It is one the revolutionary feature of driving away mosquitoes. By using this anyone can keep themselves far away from mosquitoes. Plant like Neem, Tulshi, Mint contained a great herbal characteristics. These natural products are abundantly available in nature and are widely distributed. They are cheap and not processed and can be used as raw materials for required applications. Natural repellents are identified by researchers to control the Mosquitoes. Market for fragrant clothing has also been expanded and due to increase in awareness about health and hygiene, people increasingly want their clothing to be hygienically fresh. ${ }^{5-7}$ Apart from dyeing these medicinal products give distinct odor for identification. The stem, bark, leaf, root and tuber of the plants and trees can be used for special application The chemical treatment may cause problems on human skins but the natural treatment does not create any such kind of harms rather sometimes it is very helpful to human body skin. So natural treatment is preferable against chemical ones. ${ }^{8,9}$ The repellent properties of plants to Mosquitoes and other pest insects have been well known before the advent of synthetic chemicals. However, the most commonly used insect repellents are synthetic chemicals that mostly have contained DEET (N, Ndiethyl3-methylbenzamide) and Permethrin in their formulations. Although DEET is an effective repellent against a broad spectrum of insects, however, there are disadvantages associated with the use of DEET, which stem principally from its activity as a solvent of paints, varnishes, and some plastic and synthetic fabrics. ${ }^{10,11}$ The DEET has also toxicological profile. When people get Permethrin on their skin, they may have tingling, burning, and itching at that spot if Permethrin gets in the eye, it can cause redness and pain. These treated fabrics by mosquito repellent chemicals will make revolutionary development in the upcoming days. So many projects have been completed about mosquito repellent finish. Some of them are by natural plan and some of them are by artificial and synthetic chemical. Natural sources are always preferable because they have less adverse effect on environment and always eco-friendly. ${ }^{12,13}$ Currently, different new Mosquito control devices have been developed which have the capability to control Mosquitoes and other biting arthropods. These products claim that they can dramatically decrease or even eradicate the number of Mosquitoes and other biting arthropods present by effectively trapping or repelling them from residential properties. In another study, a lethal ovitrap was designed and developed to kill dengue vectors through an impregnated insecticide-treated ovistrip has been evaluated in Rio de Janeiro, Brazil, and has shown to be effective in reducing Aedes aegypti (L.) populations in and around homes. ${ }^{14}$ 


\section{Experiment details}

\section{Materials}

In the experiment cotton fabric (woven and knit) was used as textile substrates. Both fabric samples were collected from NITER wet processing lab (Table 1).

Table I Fabric specification

\begin{tabular}{lll}
\hline Characteristics & Woven & Knit \\
\hline Count & $22 \mathrm{Ne}$ & $24 \mathrm{Ne}$ \\
EPI (Ends per inch) & 124 & - \\
PPI (Picks per inch) & 92 & - \\
CPI (Course per inch) & - & 50 \\
WPI (Wales per inch) & - & 40 \\
\hline
\end{tabular}

\section{Equipment's}

For the dyeing and pretreatment process IR Dyeing Machine was used. To complete the finishing process Padding Mangle was used for woven fabric and IR Dyeing Machine was used for knit fabric. Curing machine was used for curing and drying purpose.

\section{Methodology}

Pre-treatment $\&$ dyeing of cotton fabric: The Cotton fabric is scoured with Sodium Hydroxide $(\mathrm{NaOH})$, bleached with Hydrogen Peroxide $\left(\mathrm{H}_{2} \mathrm{O}_{2}\right)$, and dyed with Reactive dye to render it attractive to the Mosquitoes. Scouring of fabric was carried using $4 \%$ owf sodium hydroxide $(\mathrm{NaOH}) \& 0.5 \%$ owf wetting agent at temperature of $100^{\circ} \mathrm{C}$ for 1 hour. Bleaching was done using $2 \%$ owf hydrogen peroxide $\left(\mathrm{H}_{2} \mathrm{O}_{2}\right)$ at temperature $-85^{\circ} \mathrm{C}$ for 1.5 hour. Only knit fabric was dyed by using $0.5 \%$ owf reactive dye, $4.0 \mathrm{~g} / 1$ sodium carbonate $\left(\mathrm{Na}_{2} \mathrm{CO}_{3}\right)$, $40.0 \mathrm{~g} / 1$ sodium chloride $(\mathrm{NaCl})$ at temperature $80^{\circ} \mathrm{C}$ for 1 hour.

\section{Selection of medicinal plant}

At first the medicinal plants were identified and collected from natural sources both living area and forest area. For this experiment Neem, Tulshi \& Mint-leaf were chosen. The method initiates with the selection of the medicinal plants which were screened and therefore those were washed by distilled water for several times. These plants were collected since they are herbal and keep away insects (Figure 1).

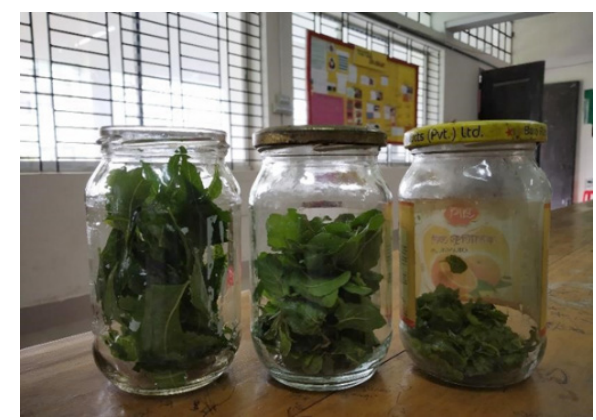

Figure I Medicinal plants.

\section{Extraction process}

According to the weight of the fabric, same amount of leaves of neem, tulshi \& mint were taken. Around $5 \mathrm{gm}$ leaves per $100 \mathrm{ml}$ methanol was taken in a glass container. Then the solution was kept in room temperature and away from sun light for 2 months so that the sunlight could not damage the solution. The solution was agitated by glass rod in every 7 days.

\section{Condensation}

The solution was filtered to get the required extracted solution. Subsequently the finishing solution was taken from the extracted solution from the evaporation process and was used to finish the fabric. The evaporation was done by burner for 2 minutes (Figure 2).

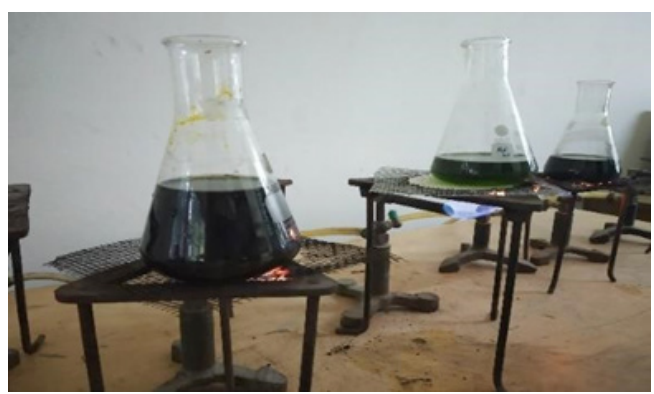

Figure 2 Condensation process.

Recipe for mosquito repellent finishing on textile materials: By pad dry cure process, woven fabric was treated and by exhaust process knit fabric was finished. In exhaust method knit fabric was finished by using 3\% owf extracted chemicals, $1 \mathrm{cc} / \mathrm{L}$ citric acid $\left(\mathrm{C}_{6} \mathrm{H}_{8} \mathrm{O}_{7}\right), 15 \mathrm{gm}$ salt $(\mathrm{NaCl}) \& 1 \mathrm{cc} / \mathrm{L}$ wetting agent at temperature $55^{\circ} \mathrm{C}$ for 20 minutes. The $\mathrm{pH}$ was near about 5.5. In pad-dry-cure method woven fabric was finished using $20 \mathrm{cc} / 1$ extracted chemicals, $1 \mathrm{cc} / \mathrm{L}$ citric acid $\left(\mathrm{C}_{6} \mathrm{H}_{8} \mathrm{O}_{7}\right)$, $30 \mathrm{gm} / \mathrm{L}$ salt $(\mathrm{NaCl}) \& 1 \mathrm{cc} / \mathrm{L}$ wetting agent. The pickup $\%$ was around 80. Then the fabric was dried at temperature of $100^{\circ} \mathrm{C}$. After that curing process was done at $160^{\circ} \mathrm{C}$ temperature for 3 minutes.

\section{Mosquito repellency behavior test}

Mosquito collection: At first some anopheles mosquito was collected from forest area. They were stored in a container which had the facility to enter air and oxygen. The mosquitos were deprived from blood and sugar for 2 hours before testing.

\section{Repellency effect testing}

Chamber test: We have tested the mosquito repellency activity of finished fabrics by using modified handmade excito chamber following by chamber method which was created by using cock sheet. ${ }^{15}$ The outer chamber of excito-repellency testing device measures $34 \mathrm{~cm} \times 32 \mathrm{~cm} \times 32 \mathrm{~cm}$ and faces the front panel with the single escape portal. The box is composed of a rear door cover, an inner glass panel with a rubber latex-sealed door, a holding frame, a screened inner chamber, an outer chamber, a front door, and an exit portal also The test was performed in day light. Few amounts of mosquitos were released in the chamber where the treated fabrics were already kept. After each test was completed, the number of Escaped specimens and those remaining inside the chamber was recorded separately for each exposure chamber, external holding cage, and paired control chamber. Escaped specimens and those remaining inside the chamber, for the treated samples, were held separately in small holding containers with food and water (Figure 3). The percentage of Mosquito repellency was calculated by the following formula:

Mosquito Repellency $\%=\frac{\text { No. Of Specimen Escaped }+ \text { No. of Specimen Dead }}{\text { No. of Specimen Exposed }} * 100$ 


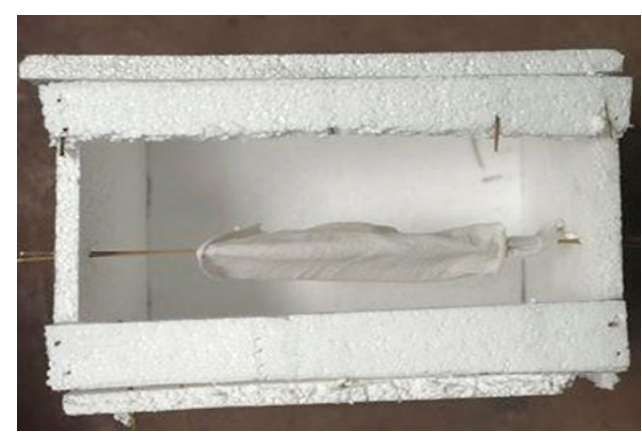

Figure 3 Excito chamber.

\section{Result \& discussion}

The research work has given a new idea in finishing of cotton fabric with medicinal plants for mosquito repellent activity. The treated fabric was found very hygienic but not same for all types of finishes. The result was checked for every fabric by using formula. The result was also checked the test after washing the fabric. The finished fabric showed a great result until $9^{\text {th }}$ wash as the extract were only coated at surface without any bonding on the fabric which were removed by repeated washing. After washing 9 times we have found that the repellency behavior of fabric was decreasing gradually. The repellency effect of fabric which was treated by tulshi leaves extracted chemicals was less than the fabrics which were treated by neem leaves and mint leaves extracted chemicals for both woven and knit fabric. After $9^{\text {th }}$ wash the tulshi leaves extracted chemicals treated fabric lost its repellency effect but other fabrics had few repellency behavior. We calculated the repellency effect of every fabric by using mosquito repellency percentage formula and made a comparison among them to identify the best repellent chemicals.

\section{Comparison}

We have finished both woven and knit cotton fabric by using herbal extract mosquito repellent chemical. The result was not same for every fabric and chemicals.

From the calculation we have found that the mosquito repellency activity of the extracted chemicals from mint and neem leaves is higher than that of tulshi leaves. In case of neem \& mint leaves the repellency percentage was $90 \%$ for both while $70 \%$ activity was found for the tulshi leaves. For both cotton woven and cotton knit fabric we obtained the same result. So it is apparent that the behavior of neem and mint leaves extract chemicals is behavior than the tulshi leaves extracted chemicals. We have also forced some mosquito to stay on the fabric but after few seconds it flew away. The total comparison is giving the below Table 2 .

Table 2 Total comparison

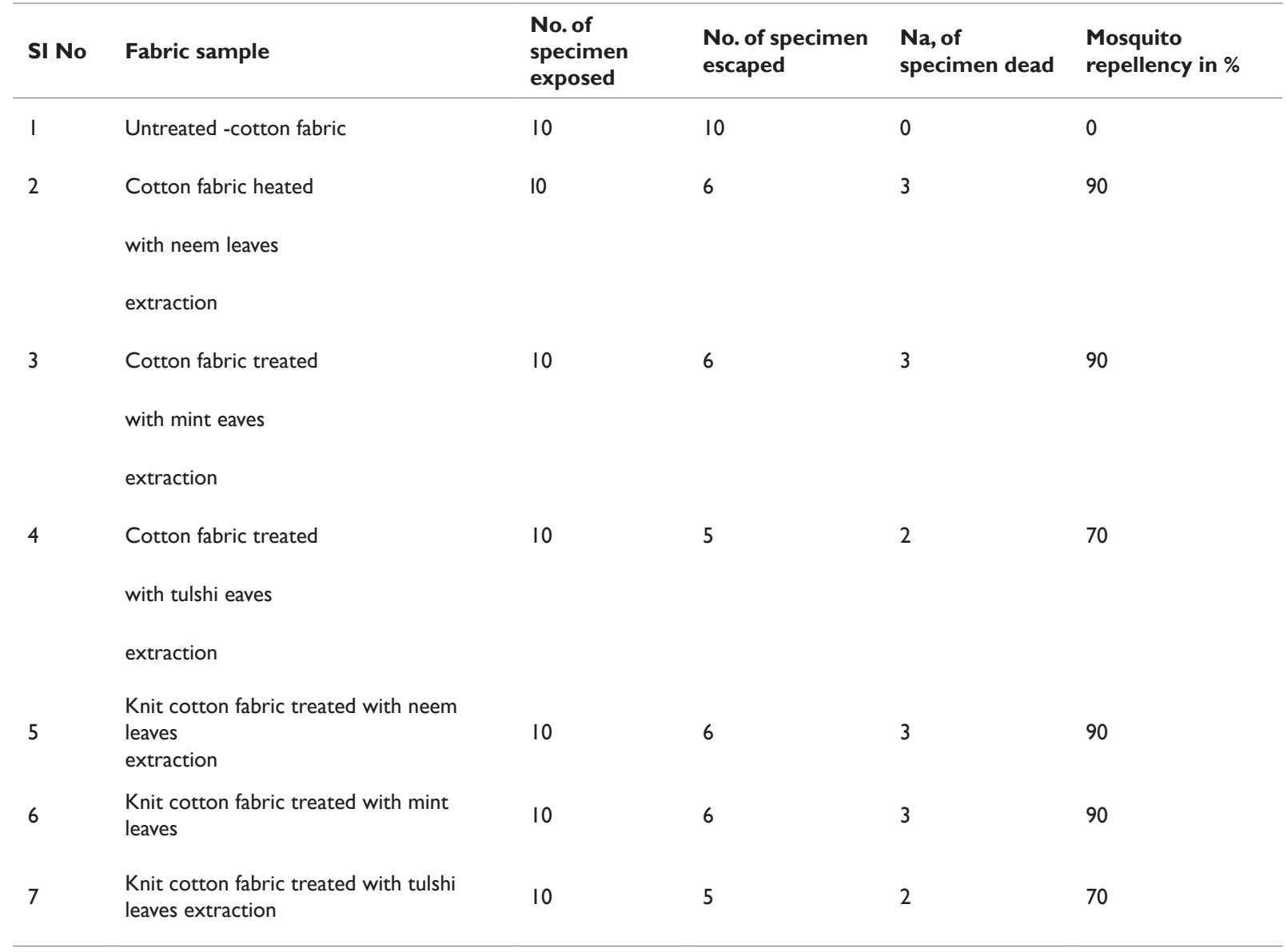




\section{Conclusion}

This research aimed to identify effective uses of textile finishes that makes the fabric repellent from mosquitoes as well as other insects.it can be a subject for a huge industrial production. Based on qualitative and quantitative analysis, it can be concluded that elements from nature has a great power and the elements has different effects on different type of fabric. The results indicate that, our country has the prominence to grab and to develop the sector. In today's world, the growing number of mosquito -borne diseases necessitates the discovery of new forms of mosquito repellents, in both synthetic and natural forms. The developed fabrics were assessed for mosquito repellent efficiency. This study proved that mosquito repellent finishes can be given to the textile materials in order to provide external protection in the form of door curtains, bed sheets, table and sofa covers to prevent the mosquito bites.

\section{Acknowledgments}

None.

\section{Funding}

None.

\section{Conflicts of interest}

The authors have no conflicts of interest regarding the publication of this paper.

\section{References}

1. Kumaravel S, Lakshmikantha CB, Ponmuruga. Mosquito repellent fabric - A comprehensive view. Textile Review. 2009:26-29.

2. Gulrajani ML, Agarwal A, Lohia C, Preparation of mosquito repellent fabrics. Asian Dyer. 2007:53-55.

3. Mia R, Selim M, Shamim A, et al. Review on various types of pollution problem in textile dyeing \& printing industries of Bangladesh and recommandation for mitigation. Journal of Textile Engineering \& Fashion Technology. 2019;5(4):220-226.
4. MB. Analysis and characterization of mosquito repellent textiles. $J$ Textile Sci Eng. 2017;7(5):10-21.

5. MS Karolia A. Application of antimicrobial and fragrance finish in combination by microencapsulation on cotton fabric. Journal of the Textile Association. 2005:155-159.

6. Al Mojnun Shamim SS, Mia R, Selim M, et al. Reuse of standing dye bath of reactive dyeing with nylon \& silk. International journal of engineering sciences \& research technology. 2019;70(90):5-30.

7. Mia R, Islam MA, Ahmed B, et al. Woolenization of Jute Fibre. Textile Today; 2016.

8. NL Premalatha R. Herbal finishing on woven fabrics. National Conference on ACTPAQ; 2007:88-92.

9. Banna et al BU, Mia R, Tanni KS, et al. Effectiveness of dyeing with dye extracted from mango leaves on different fabrics by using various mordants. 2019.

10. GR Oshaghi MA, Vatandoost H, Shayeghi M, et al. Repellent effect of extracts and essential oils of Citrus limon (Rutaceae) and Melissa officinalis (Labiatae) against main malaria vector, Anopheles stephensi (Diptera: Culicidae. Iranian J Publ Health. 2003:32:37-52.

11. Ahmed T, Mia R, Tanjim M. An extensive analysis of the health hazards for RMG workers in apparel sector of Bangladesh. J Textile Eng Fashion Technol. 2020;6(4):141-146.

12. JL Sayed U. Application of herbs on fabrics. Supplement to Colourage. 2006;4:129-133.

13. Sizan NTN, Ali MF, Mia R. Evaluate the dyeing performance of silk fabric by using four different reactive dyes. 2019.

14. KA Perich MJ, Braga IA, Portal IF, et al. Field evaluation of a lethal ovitrap against dengue vectors in Brazil. Med Vet Entomol. 2003;17:205210 .

15. Roberts DR, Chareonviriyaphap T, Harlan HH, et al. Methods for testing and analyzing excito-repellency responses of malaria vectors to insecticides. J Am Mosq Contr Assoc. 1997;13:13-17. 